\title{
The 15th century Arctic warming in coupled model simulations with data assimilation
}

\author{
E. Crespin ${ }^{1}$, H. Goosse ${ }^{1}$, T. Fichefet ${ }^{1}$, and M. E. Mann ${ }^{2}$ \\ ${ }^{1}$ Université catholique de Louvain, Institut d'Astronomie et de Géophysique Georges Lemaître, Chemin du Cyclotron, 2, \\ 1348 Louvain-la-Neuve, Belgium \\ ${ }^{2}$ Department of Meteorology, Department of Geosciences, and Earth and Environmental Systems Institute, Pennsylvania \\ State University, University Park, USA
}

Received: 4 November 2008 - Published in Clim. Past Discuss.: 7 January 2009

Revised: 30 April 2009 - Accepted: 7 July 2009 - Published: 22 July 2009

\begin{abstract}
An ensemble of simulations of the climate of the past millennium conducted with a three-dimensional climate model of intermediate complexity are constrained to follow temperature histories obtained from a recent compilation of well-calibrated surface temperature proxies using a simple data assimilation technique. Those simulations provide a reconstruction of the climate of the Arctic that is compatible with the model physics, the forcing applied and the proxy records. Available observational data, proxybased reconstructions and our model results suggest that the Arctic climate is characterized by substantial variations in surface temperature over the past millennium. Though the most recent decades are likely to be the warmest of the past millennium, we find evidence for substantial past warming episodes in the Arctic. In particular, our model reconstructions show a prominent warm event during the period 14701520. This warm period is likely related to the internal variability of the climate system, that is the variability present in the absence of any change in external forcing. We examine the roles of competing mechanisms that could potentially produce this anomaly. This study leads us to conclude that changes in atmospheric circulation, through enhanced southwesterly winds towards northern Europe, Siberia and Canada, are likely the main cause of the late 15th/early 16th century Arctic warming.
\end{abstract}

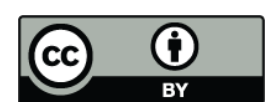

Correspondence to: E. Crespin (elisabeth.crespin@uclouvain.be)

\section{Introduction}

Studies of the Arctic climate indicate a considerable warming in this region in recent decades. For the past 100 years, the Arctic has warmed twice as much as the global average (Trenberth et al., 2007). This warming has been associated with a substantial diminution of sea ice thickness (Serreze et al., 2000) and extent (Meier et al., 2005).

While recent Arctic warmth appears anomalous, observational and proxy data indicate substantial long-term temperature variability in the region. A multidecadal interval of relative warmth, for example, can be found during the early 20 th century, between the 1920s and 1940s, when conditions were only slightly less warm than today (Johannessen et al., 2004). While instrumental temperature data are relatively sparse during the first half of the last century, the early 20th century Arctic warm period appears to have been characterized by a large-scale spatial pattern different from the current warm period. The early 20 th century warming was largely confined to the Arctic alone (i.e. the region north of $60^{\circ} \mathrm{N}$ ), while the recent warming has been more widespread, with a pronounced warming in the Eurasian mid-latitudes (Kuzmina et al., 2008; Trenberth et al., 2007; Johannessen et al., 2004; Overland et al., 2004).

The dynamical processes underlying those two Arctic warm periods are also likely different. For the most recent decades, it is almost certain that the anthropogenic greenhouse gas forcing has dominated over the contribution from internal variability (defined here as the variability related to the internal dynamics of the climate system, i.e. that would be present in the absence of any change in natural or anthropogenic forcing) (Johannessen et al., 2004), though the

Published by Copernicus Publications on behalf of the European Geosciences Union. 
extent of the role played by natural multidecadal variability has not yet been entirely resolved (Polyakov and Johnson, 2000). By contrast, during the early 20th century when anthropogenic forcing was considerably weaker than today, the observed Arctic warming was likely due, at least in substantial part, to the natural variability of the climate system. The natural external forcing resulting from solar irradiance variations and volcanic eruptions could have played some role in this early warming, but the precise role is difficult to assess due to the uncertainties in the forcings. It has been proposed that the early 20th century warming was caused by increased southwesterly winds and oceanic heat transport into the Barents Sea region (Bengtsson et al., 2004; Overland et al., 2004; Rogers, 1985). There is evidence that these changes were, in turn, associated with purely internal, multidecadal oscillatory variability of the climate system (Bengtsson et al., 2004; Johannessen et al., 2004; Overland et al., 2004; Delworth and Mann, 2000; Delworth and Knutson, 2000; Przybylak et al., 2000; Mann and Park, 1994).

The absence of widespread direct instrumental data before the mid-19th century at high latitudes (though there are sparse records reaching back to the late 18th century, e.g. Moberg et al., 2003; Vinther et al., 2006) requires the use of climate "proxies", such as tree rings, ice cores, lake sediments and historical documents, from which we can infer some key characteristics of climate changes in past centuries. Such compilations for high northern latitudes (e.g. Jiang et al., 2005; Jennings and Weiner, 1996; Massé et al., 2008; D'Arrigo and Jacoby, 1993; Jacoby et D' Arrigo, 1989; Overpeck et al., 1997; Ogilvie and Jónsson, 2001) suggest that similar Arctic warm events may have occurred in past centuries. In this study, we focus on the evidence and dynamical explanations for any such extended periods of Arctic warmth during the past millennium. Proxy reconstructions of global or hemispheric mean surface temperature (e.g. Mann et al., 1999, 2005b, 2008; Briffa et al., 2001; Jones et al., 2001; Esper et al., 2002; Mann and Jones, 2003; Jones and Mann, 2004; Jansen et al., 2007) reveal the existence of a period of modest large-scale warmth covering the 10th to 12th centuries, though it does not rival current warmth. This so-called "Medieval Warm Period" is followed by a period of relative large-scale coolness over the 15th-19th centuries known as the "Little-Ice Age". At the hemispheric or global scale, these temperature changes are largely consistent with the response of the climate system to external changes over the past millennium in natural (and after the 19th century, anthropogenic) radiative forcing (e.g. Crowley, 2000). At regional or local scales, however, the influence of the forced response of the climate may be overwhelmed by the contribution of internal climate dynamical processes (Goosse et al., 2005).

In this study, we seek, as in previous studies (e.g. Goosse et al., 2008), to merge the observational information contained in available proxy records with the physical and dynamical constraints present in forced climate model simulations to interpret past climate changes. Our focus is on using such analyses to interpret the impacts of large-scale dynamics, as well as radiative forcing changes, on the inferred pattern of past regional temperature changes.

We employed LOVECLIM1.1 (Goosse et al., 2007) for our model simulations. A set of five different experiments covering the past millennium were run with data assimilation. More specifically, the evolution of the model was constrained by selecting, among all available realizations, the realization of the internal variability that most closely matches the information from the proxies. Those estimates of past climate changes based on model simulations using data assimilation will be referred to as "reconstructions", even though the methodology used in this framework differs from the more traditional, statistically-based approach to reconstructing climate over the past millennium. The model simulations allow us to advance hypotheses about the mechanisms associated with any particular interval of Arctic regional warming. We performed a parallel ensemble of simulations without data assimilation. The ensemble mean in the latter case can be used to define the response of the system to the external forcing alone, since the influence of the natural internal variability, which differs from one realization to another, is heavily damped by the averaging process. Comparisons between these two parallel sets of experiments allow us to isolate the relative contributions of both external forcing and internal variability.

We first describe the model and experimental design, the forcings applied and the data assimilation technique. The assimilated proxy records are taken from a recent compilation (Mann et al., 2008) of a large network of high-resolution (that is, decadally or annually-resolved) climate proxy data. Our focus is on a particularly warm event taking place during the period 1470-1520 that is evident in the proxy data. Using the model data assimilation experiments, we analyze the role of various physical and dynamical processes that appear responsible for the pattern of the observed Arctic warmth, and demonstrate that this pattern likely arises from dynamical variability.

\section{Model description and experimental design}

The different simulations examined in this study were performed with LOVECLIM1.1 (Driesschaert et al., 2007; Goosse et al., 2007), a three-dimensional climate model of intermediate complexity which includes representations of the atmosphere, the ocean and sea ice, the terrestrial biosphere, the oceanic carbon cycle and the polar ice sheets. As the last two components were not activated in this study, they will not be described here. The atmospheric component of LOVECLIM is ECBILT2 (Opsteegh et al., 1998), a quasi-geostrophic model of horizontal resolution T21 and three vertical levels, with simple parameterisations for the diabatic heating due to radiative fluxes, the release of latent heat, and the exchanges of sensible heat with the surface. 
a)

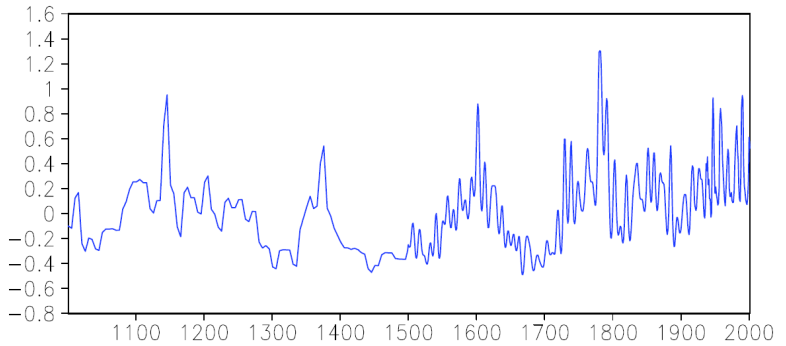

b)

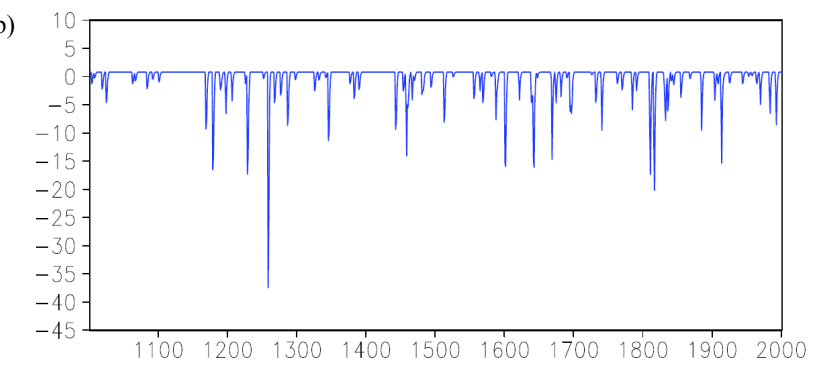

c)

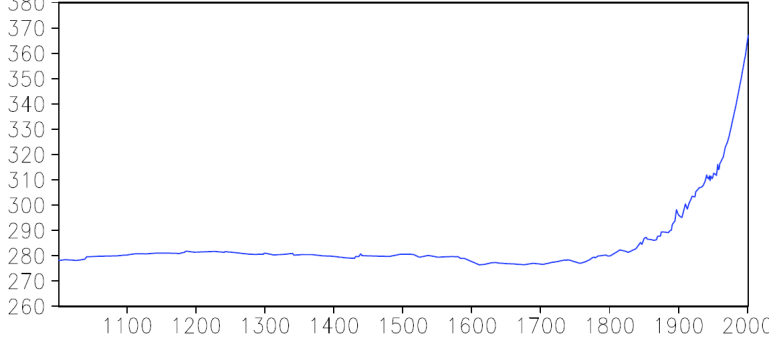

Fig. 1. (a) Global mean radiative forcing $\left(\mathrm{W} / \mathrm{m}^{2}\right)$ used to drive LOVECLIM simulations for the last 1000 years associated to variations in the total solar irradiance based on Muscheler et al. (2007). (b) Radiative forcing $\left(\mathrm{W} / \mathrm{m}^{2}\right)$ associated to volcanic activity according to Crowley (2000) for the region including latitudes from $35^{\circ} \mathrm{N}$ to $90^{\circ} \mathrm{N}$, incorporated in LOVECLIM through a modification in the solar irradiance. (c) Time series of $\mathrm{CO}_{2}$ concentrations (ppmv).

The oceanic component is CLIO3 (Goosse and Fichefet, 1999). This model is made up of a primitive-equation, free-surface ocean general circulation model coupled to a thermodynamic-dynamic sea-ice model. Its horizontal resolution is $3^{\circ}$ in longitude and latitude, and there are 20 unevenly spaced vertical levels in the ocean. The terrestrial vegetation module VECODE (Brovkin et al., 2002) computes annually the evolution of trees, grass and deserts. It has the same resolution as ECBILT. More information about the model can be obtained at: http://www.astr.ucl.ac.be/index. php?page=LOVECLIM\%40Description .

All the simulations were driven by the same forcings. The model includes three natural forcings, namely the changes in the Earth's orbital parameters, the volcanic activity and the variations in solar irradiance, as well as three anthropogenic forcings, i.e., the changes in greenhouse gas concentrations, including tropospheric ozone, the variations in sulphate aerosol loading, and the forcing due to changes in land-use. The temporal evolution of some of these forcings is shown in Fig. 1. The variations of the Earth's orbital parameters follow Berger (1978). The effect of volcanism is derived from Crowley (2000) and is included through changes in solar irradiance. The evolution of solar irradiance follows the reconstruction of Muscheler et al. (2007). The evolution of greenhouse gas concentrations is based on a compilation of ice cores measurements (J. Flueckiger, personal communication, 2004). The influence of anthropogenic sulphate aerosols is taken into account through a modification of surface albedo (Charlson et al., 1991). The changes in land-use are based on Ramankutty and Foley (1999) and are applied in the model through a reduction in the area covered by trees and an increase in grassland as VECODE does not include a specific vegetation type corresponding to cropland.

The goal of this study is to obtain a simulation of the Arctic climate for the last millennium that is not only consistent with our model and the forcings applied, but also with the data available for that period. For that purpose, we constrain the model results using the recent compilation of well-calibrated surface temperature proxy records of Mann et al. (2008) and a new version (see Goosse et al., 2009) of the data assimilation technique described in Goosse et al. (2006). We proceed in the following manner: we start the simulation at the year 1000, from a condition obtained from a long simulation covering the whole Holocene (Goosse et al., 2007). By introducing small perturbations in the atmospheric streamfunction, we generate an ensemble of 96 simulations for a short period of time (1, 5, 10 or 20 years). We choose the number of ensemble members for technical reasons: we want around a hundred simulations in order to have enough realizations of the internal variability of the system, and it is easier to run 96 simulations in parallel ( 3 groups of 32 simulations, each of them on 32 CPUs of a cluster). Then, we select among those 96 representations of the model internal variability the one that is the closest to the proxy records available for the period of time investigated. This is achieved by using the following cost function:

$C F_{k}(t)=\sqrt{\sum_{i=1}^{n} w_{i}\left(F_{\text {obs }}(t)-F_{\text {mod }}^{k}(t)\right)^{2}}$

$C F_{k}(t)$ is the value of the cost function for each member $k$ of the ensemble for a particular period $t . n$ is the number of proxies used in the model/data comparison. $F_{\text {obs }}(t)$ is the value of the variable $F$ (the surface temperature in this case) in the proxy records at the location where they are available, and $F_{\text {mod }}^{k}(t)$ is the value of the same variable simulated by the model in the simulation $k$ at the same location as the proxy record. $w_{i}$ is a weight factor. The experiment $k$ which minimizes the cost function $C F_{k}$ is selected for that particular period of time, and the end of this simulation is used as the basis for the initial condition of the new ensemble of simulations performed over the next period. The procedure follows in the same way for the whole millennium. As this method 
requires a large number of simulations, LOVECLIM coarse resolution and low computer-time requirements are appropriate.

A set of 56 annual or decadally-resolved proxy series (or regional composites thereof) screened for a local temperature signal (Mann et al., 2008) is used to constrain the model. The proxy data set is derived largely from tree-rings, ice cores, some lake sediments and historical documents. The screening procedure retains only those proxy data exhibiting a statistically significant correlation with local (5 degree latitude $\times$ longitude) gridbox instrumental surface temperature data (Brohan et al., 2006) during the calibration interval (1850-1995). When proxy records reflect temperature variations at sub-annual resolution, they are averaged to obtain annual mean values. All proxy records available over a gridbox region are averaged to produce a regional gridbox composite. The proxy gridbox series are then decadally-smoothed using a low pass filter, and averaged and scaled to the same mean and decadal standard deviation as the associated instrumental gridbox temperature series over the calibration period. For the purpose of the ensuing analysis, we have kept only those records available back to the year 1400 , and which extend through 1995 . The proxy data are primarily terrestrial, and cover tropical, extratropical, and polar regions, though the greatest coverage is provided northward of $30^{\circ} \mathrm{N}$. The locations of the proxy gridbox series available in the Arctic region over the time interval of our analysis are shown in Fig. 3. The available data sample Scandinavia, Siberia and western North America, while there is a dearth of coverage in certain regions such as eastern North America.

We present in this paper the results obtained from 5 different numerical experiments using data assimilation. They start from the same initial conditions, but use different approaches to placing constraints on the model and different periods of time in the computation of the cost function. In the first experiment, the weight factors $w_{i}$ are the same for all the proxy records and the cost function is evaluated for 1year averages. In the other four simulations, in order to give a larger weight to proxies which are more reliable, the value of the weight factors $w_{i}$ is proportional to the correlation between the proxy records and the observations of temperature obtained during the instrumental period. In these 4 experiments, the averaging period in the computation of the cost function is set to $1,5,10$ and 20 years, in order to test if this has an impact on our results. For instance, for 20-year mean, processes responsible for interannual variability may be filtered, while they can play an important role in the selection of the best experiment when 1-year mean are analyzed. These different experiments allow us to test the robustness of our results, by assuring that we obtain similar and internally consistent results regardless of the precise method by which we constrain the model evolution to be consistent with the proxy data. The ensemble mean over the 5 experiments provides a better estimate of the true climatic variability by averaging out the 'noise', while the within-ensemble variance provides an appropriate estimate of the component of uncertainty associated with the sensitivity to the precise constraint method used.

In addition, an ensemble of 10 simulations was performed without data assimilation. This ensemble was run with the same model and the same forcings used in the simulations with data assimilation, but with slightly different initial conditions used for each ensemble member. The ensemble mean allows us to diagnose the response of the system only to the external forcings, and by comparing it with the experiments with data assimilation, we can attempt to separate the relative roles of internal variability and external forcing in the observed climate history.

\section{Validation of the assimilation method using modern observations}

In order to test the ability of the model to follow true, observed changes when using the method described in Sect. 2, a validation exercise was performed in which we assimilated HadCRUT3 annual surface temperature observations (Brohan et al., 2006) between years 1850 and 2000. In the first experiment, we constrained the model with observed temperatures over the region located northward of $30^{\circ} \mathrm{N}$. We divided this region into six boxes: Atlantic, Pacific, Europe, Asia, America and Arctic. The average surface temperature over each box was computed for both the observational data and the model results, using only those locations where observations are available, and the cost function was then evaluated using these six averages. This approach insures that each region has the same weight, even if one region has less data than another (this approach is similar to that used for examining surface temperatures in the Southern Hemisphere by Goosse et al., 2009). In a second experiment, we constrained the model using only the instrumental surface temperature observations at gridboxes where proxy data are available. This exercise was used to establish whether the model can successfully reproduce a coherent evolution of the surface temperature field when constrained only with relatively sparse data, as it is the case when using proxy networks such as that used in our current study.

Figure 2 shows the results from these model simulations. Each experiment was conducted twice, using an averaging period of 1 and 5 years, respectively, for the computation of the cost function. The agreement between the simulated surface temperatures and observations in the Arctic (region northward of $64^{\circ} \mathrm{N}$ ) is reasonably good for the 20th century. The experiments performed with the complete HadCRUT3 data set (dark and light blue curves) are very close to the observations (red curve). Likewise, the experiments using the sparser "proxy site" observations (dark and light green curves), are also in good agreement with the observations. While the sparseness of the available proxy data is a primary limiting factor with the technique used in this study, 


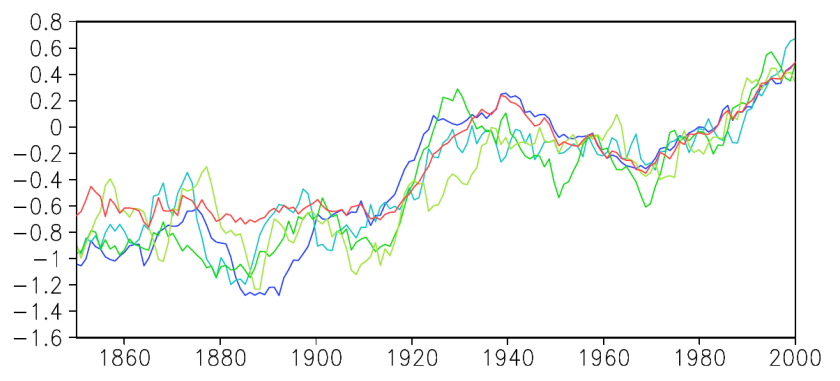

Fig. 2. Anomaly in annual mean surface temperature $\left({ }^{\circ} \mathrm{C}\right)$ in the Arctic over the last 150 years. The red line is the HadCRUT3 data set (Brohan et al., 2006). The dark and light blue lines are the results from model simulations using the complete HadCRUT3 data set to constrain the model, for the cost function evaluated for 1 and 5 years averages respectively. The dark and light green lines are the results from model simulations constrained by data from HadCRUT3 only at the locations where proxies are available, for the cost function evaluated for 1 and 5 years averages respectively. An 11-year running mean has been applied to the time series. The reference period is $1960-2000$.

we nevertheless find that the model yields satisfactory results for the Arctic, even when constrained by relatively sparse observations at high latitudes ( 23 series North of $55^{\circ} \mathrm{N}$ in this case).

\section{Comparison of model results with proxy data}

Before analyzing the climate evolution obtained in our simulations over the past millennium, we sought to establish the robustness of the technique of data assimilation and the quality of model results by comparing them with the proxy records used to constrain the model. The comparison between the annual mean surface temperature anomaly pattern directly indicated by the proxies and the model simulation (we have retained only those model locations where proxy information is available) is shown in Fig. 3. We chose to examine a representative set of warm and cold periods, averaged over 50 years, which take place during years 1470 1520 and 1600-1650, respectively. In general, the spatial pattern of surface temperature simulated in the model is reasonably close to the proxy data, although some substantial local differences can be observed, for example over the North American region. Possible explanations for these local discrepancies are that (i) the proxies contain sizeable non-climatic sources of noise or bias which are not correlated over local scales, and that (ii) the model may be deficient in representing the variability at such scales (i.e. one model gridbox). Both factors could lead to substantial local differences between model results and the proxy observations. On the other hand, as shown in Fig. 4, the model results exhibit a better agreement with proxy records at regional scales. The temporal evolution of surface temperature

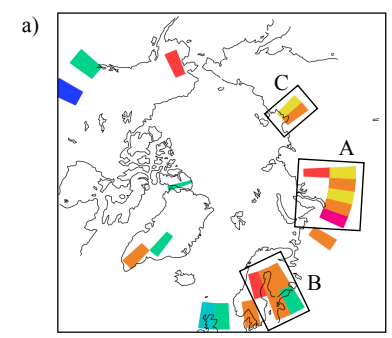

b)
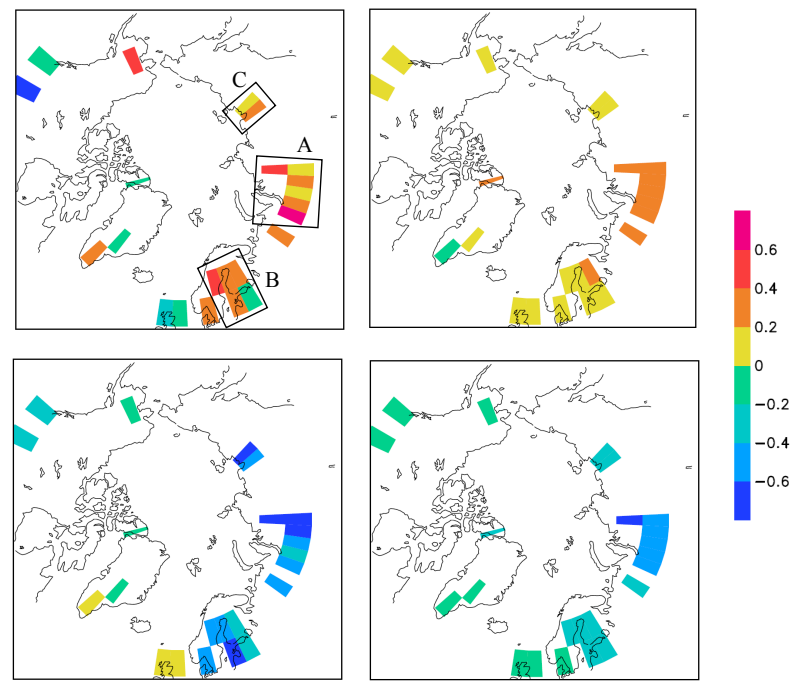

Fig. 3. Anomaly in annual mean surface temperature $\left({ }^{\circ} \mathrm{C}\right)$ during a warm and a cold period in the proxy data (left column) and the model results averaged over the 5 simulations (right column). The model results are shown only at the locations where the proxies are available. (a) 1470-1520 and (b) 1600-1650. The reference period is 1600-1950. The boxes in a) correspond to the regions over which averages are performed to obtain the time series shown in Fig. 4.

averaged over three representative regions where proxies are available (boxes in Fig. 3a define these different regions), indicates good agreement between the surface temperature computed in each one of the 5 model simulations and the proxy-based reconstruction. For the average over each region, we measure the misfit between model results (mean of the 5 experiments) and proxy series by calculating the root mean-square error (RMSE) for the period 1400-1995. In the first (RMSE $=0.08$ ) and second (RMSE=0.1) regions, all simulations are in good agreement with the proxy records. The third region $(\mathrm{RMSE}=0.21)$ presents good results as well, although some discrepancies with proxy data and a larger variance between model simulations is observed. For instance, the amplitude of the early 17 th century cooling in that region is larger in the proxies than in the different model simulations, and this minimum is shifted.

In Fig. 4.d, we compare the annual mean surface temperature averaged over the whole Arctic obtained in the different simulations with the high-latitude summer-weighted annual temperature reconstruction of Overpeck et al. (1997). It is worth mentioning that this reconstruction is not totally independent from ours, since some of their proxies are also included in this study. The "Little Ice Age" and subsequent warming recorded by this compilation are reproduced in the model simulations. The agreement between model and proxy data is quite good overall, though the mid-19th century is colder in the Overpeck et al. (1997) reconstruction than in our model. The model also tends to simulate slightly too high temperatures at the end of the 20th century. 


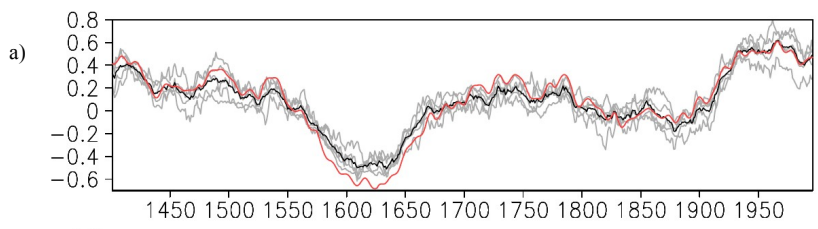

b)

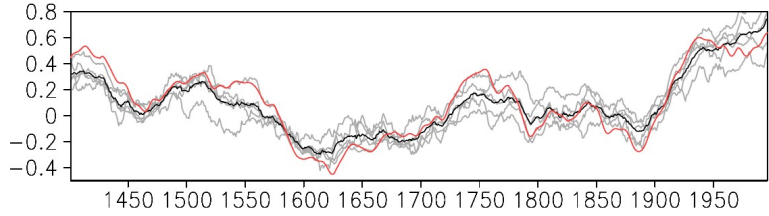

c)
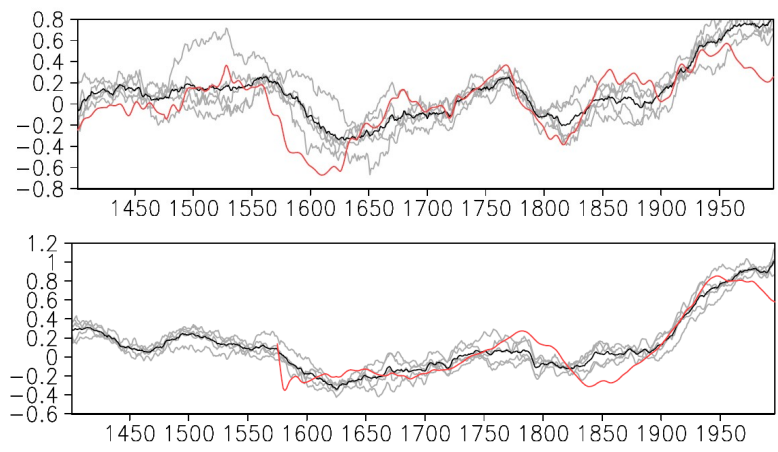

Fig. 4. (a) Time series of the anomaly in annual mean surface temperature $\left({ }^{\circ} \mathrm{C}\right)$ over the last 600 years for the region in the box $\mathrm{A}$ in Fig. 3. The black line is the mean over the 5 model simulations, the red line is the average over the 6 proxy data contained in box A in Fig. 3, and the grey lines are the results of the 5 different model simulations. (b) Same as a) for the mean over box B in Fig. 3 (5 proxies). (c) Same as a) for the mean over box C in Fig. 3 (2 proxies). (d) Anomaly of annual mean surface temperature in the Arctic for the last 600 years. The Arctic area corresponds to the mean over all longitudes between $64^{\circ} \mathrm{N}$ and $80^{\circ} \mathrm{N}$. The red curve is the reconstruction of Overpeck et al. (1997). A 51-year running mean has been applied to all time series. The reference period is 1600-1950.

\section{The 1470-1520 warm period}

The annual mean surface temperature in the Arctic in the 5 simulations including data assimilation (Fig. 5a, blue curve) shows the relative warmth during the first five centuries that is evident in hemispheric climate reconstructions (e.g. Jansen et al., 2007; Mann et al., 2008). The mean surface temperature northward of $64^{\circ} \mathrm{N}$ during the 12 th century is about $0.2^{\circ} \mathrm{C}$ warmer than over the reference period 1600-1950. The cooling that follows, starting at the beginning of the 13th century, is interrupted by some warming periods. Two important peaks of temperature are observed during the periods 1400-1450 and 1470-1520. They correspond to the warmest periods of the last millennium before the industrial period for the mean over the five experiments, i.e. that, in our simulations, they are warmer than the so-called "Medieval Warm Period" in the Arctic. The "Little Ice Age" then follows, with relatively cool temperatures during the 16 th, 17 th and 19 th centuries. From the beginning of the 20th century to
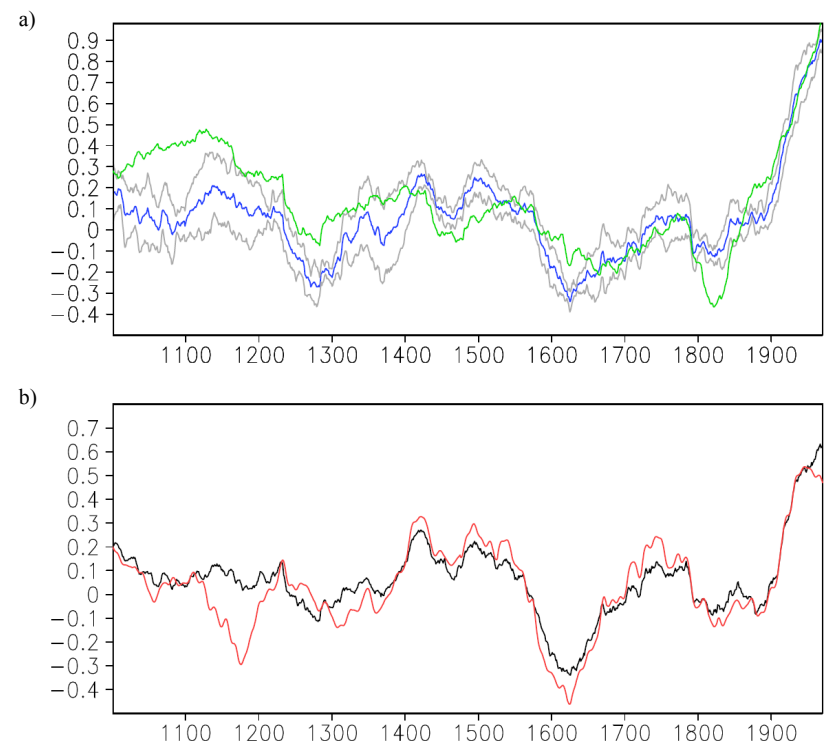

Fig. 5. Anomaly in annual mean surface temperature $\left({ }^{\circ} \mathrm{C}\right)$ in the Arctic over the past millennium. (a) The blue line is the average over the 5 model simulations performed with data assimilation, and the grey lines are the mean plus and minus one standard deviation of the ensemble. The green curve is the mean of an ensemble of 10 simulations made without data assimilation. (b) The red line corresponds to the average of the proxy series used to constrain the model over the Arctic. The black line represents the mean of the 5 model simulations with data assimilation averaged over the grid points where proxies are available. A 51-year running mean has been applied to the time series. The reference period is $1600-1950$.

the present, there was an abrupt increasing trend in surface temperature, associated with anthropogenic forcing.

As an expected result of the data assimilation method, from the 14th century onwards, the mean over the Arctic of the proxy data used to constrain the model (Fig. 5b, red curve) exhibits almost the same temperature evolution than the mean of the model results taken only at the locations where the proxies are available (Fig. 5b, black curve). In particular, we observe in the proxy series the two maxima of temperature during the years 1400-1450 and 1470-1520. Their presence in our simulation with data assimilation is thus clearly related to the signal recorded by the proxies. For the first 4 centuries, the model is less constrained by the proxies, the number of proxies available during this period being probably too small in the Arctic region. The largest discrepancy is observed at the end of the 12th century where proxies recorded a clear cooling.

The scatter between the 5 experiments with data assimilation (Fig. 5a, grey curves) is measured by the standard deviation of the 5 members. During the first 4 centuries of the last millennium, a fewer number of proxies is available. The variance between the different model simulations is thus larger than for the next centuries. The low standard 
deviation observed for the 15th century period (standard deviation $=0.06^{\circ} \mathrm{C}$ ) indicates that the uncertainty of our results is relatively small.

To interpret the simulated temperature changes, we compare our experiments with data assimilation with those without data assimilation (forced response). The peak medieval Arctic warmth is greater in the simulations without data assimilation (Fig. 5a, green curve). Averaged over the years 1100 to 1150 , the temperature is almost $0.5^{\circ} \mathrm{C}$ higher than the mean over the reference period in the forced response. The millennial-scale cooling trend (approximately half a degree over the millennium) is thus more pronounced in the forced response than in the simulations with data assimilation. Several causes might be responsible for this discrepancy. The forcing used in the model (and thus the forced response) is uncertain and prone to potential systematic error (e.g. Jones and Mann, 2004). Internal variability of the system at any low-frequency may induce a cooling in the Arctic, counterbalancing the effect of the forcing. On the other hand, there are uncertainties in the proxy temperature reconstructions themselves, which become increasingly substantial in the earlier centuries of the past millennium (Mann et al., 2008) and the number of proxies available for the data assimilation is low during the first 4 centuries. Although this difference between the simulations with data assimilation and without is intriguing, we will thus focus in this study on a period for which we have more data and thus likely more robust results: the period 1470-1520, corresponding to warmest period of the millennium before the 20th century.

The first maximum of temperature observed during the period 1400-1450 appears consistent with the forcing: it has low volcanic activity and is preceded by a maximum of the solar forcing $\left(0.5 \mathrm{~W} / \mathrm{m}^{2}\right)$ (see Fig. 1). By contrast, the second maximum of temperature taking place during the period $1470-1520$ is less clear in the forced response of the model. It is possible that the response of the model to the external forcings is actually not correct and that the data assimilation technique takes charge to head the system in the good direction. For instance, the response of the atmospheric circulation to external forcings, such as solar and volcanic forcings, is weak in LOVECLIM (Goosse and Renssen, 2004), while it has been suggested that the Arctic Oscillation/North Atlantic Oscillation (e.g. Shindell et al., 2001) and El Niño-Southern Oscillation (Mann et al., 2005a) response to external radiative forcings has a strong impact on past regional climatic changes. However, the period 1470-1520 corresponds to a minimum $\left(-0.3 \mathrm{~W} / \mathrm{m}^{2}\right)$ in the solar forcing which would rather lead to a cooling over large parts of the Arctic, even if the dynamical response is taken into account (Shindell et al., 2001), and it does not include any explosive volcanic events (Fig. 1). It is thus difficult to envision a substantial role for external forcings. It appears considerably more likely that this event arises simply as a realization of the internal variability of the system.

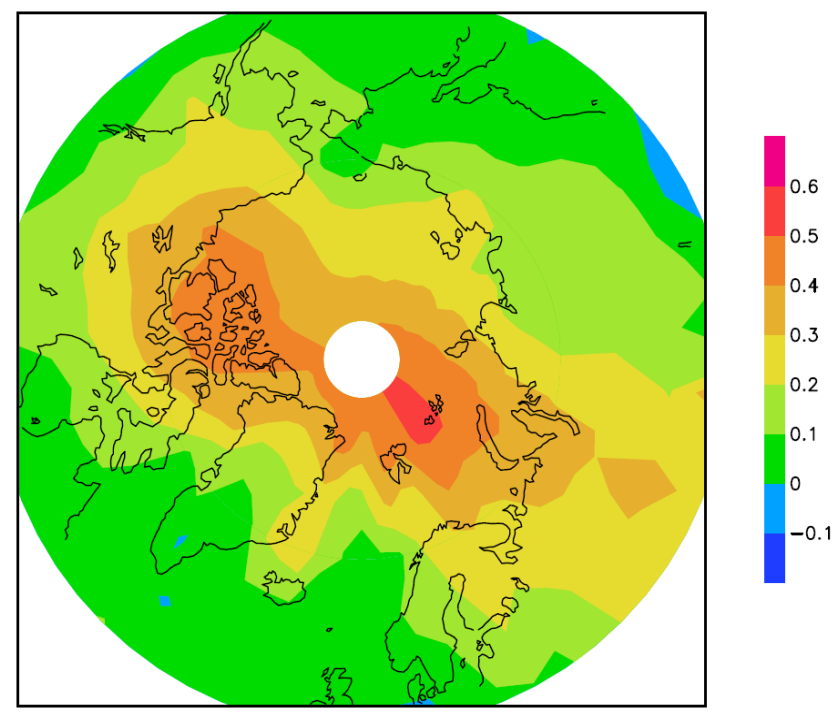

Fig. 6. Anomaly in annual mean surface temperature $\left({ }^{\circ} \mathrm{C}\right)$ over the 1470-1520 warm period for the model results averaged over the 5 simulations with data assimilation. The reference period is 1600 1950.

In order to find the causes of the changes in temperature during the period 1470-1520 simulated by our model including data assimilation, we analyze the anomalies in atmospheric and oceanic heat transports, an information not available from proxy records. The mean of the 5 model simulations performed with data assimilation is used in the following patterns.

The simulated spatial distribution of annual surface temperature anomaly for the warm period averaged over the years 1470 to 1520 (Fig. 6), shows an overall warming over the Arctic region. The few proxy records available in this region (23 proxy series North of $55^{\circ} \mathrm{N}$ ) for that period are in good agreement with the model results (Fig. 3a). This pattern is robust in our model as each individual simulation gives similar ones (not shown). The largest warming is observed in the Canadian Archipelago and Eurasian Arctic, with the maximum in the Barents Sea, whose temperature is almost $0.6^{\circ} \mathrm{C}$ higher than in the reference period.

The pattern of the annual mean anomaly of the geopotential at $800 \mathrm{hPa}$, averaged over the period 1470-1520 (Fig. 7), is consistent with the particularly warm conditions of that period. The negative anomaly west of Iceland produces an increased inflow of warm air coming from the south, leading to the warming over northern Europe, the Barents Sea and the Western Siberian region. Similarly, the negative anomaly centered over the Bering Strait induces a warming over Canada. By contrast, in regions characterized by winds anomaly coming from the north, such as the Baffin Bay and the Eastern Siberia, the temperature anomaly is weak and even negative in some regions. The geopotential anomaly corresponds thus to the right combination of anomalies in 


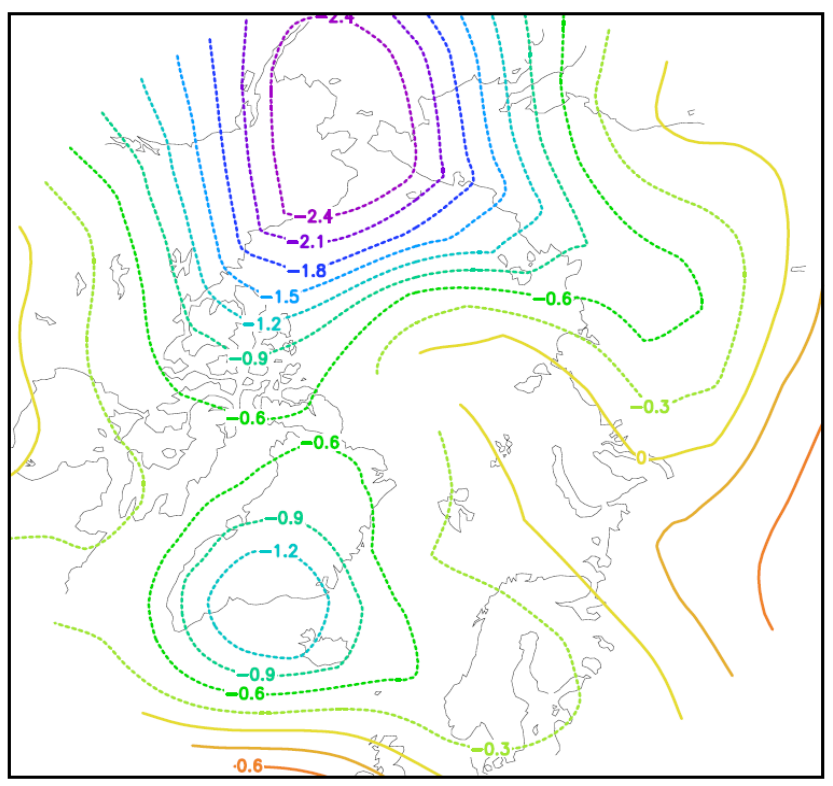

Fig. 7. Anomaly in annual mean $800 \mathrm{hPa}$ geopotential height (m) over the 1470-1520 warm period for the model results averaged over the 5 simulations with data assimilation. The reference period is $1600-1950$.

both the Atlantic and Pacific sectors that leads to a warming of nearly all regions in the Arctic and a clear signal on the regional mean shown in Fig. 6.

The pattern of surface temperature anomaly in the simulation performed without data assimilation for the period of interest 1470-1520 (not shown) is not at all similar to the one observed in the simulation with data assimilation. A weak cooling (up to $-0.1^{\circ}$ relative to the reference period) is even observed over large areas in North America and Siberia. The pattern of anomaly of the $800 \mathrm{hPa}$ geopotential height is neither similar. This clearly shows that, if not helping the model through constraining internal variability in the simulations, the external forcings are not able to induce a large scale warming as described in the proxies (Fig. 3a) and thus the role of these external forcings in our model is weak.

The behavior of the sea ice is consistent with the evolution of the surface temperature. For the whole Arctic, we notice a decrease of approximatively $2 \%$ in sea ice area and $6 \%$ in sea ice volume between the periods $1250-1300$ and 14701520. The decrease in annual mean sea ice concentration is the largest in the Eurasian Arctic and the North of Canada, while a small increase is seen in Chukchi Sea (Fig. 8) compared to the reference period. A minimum in sea ice concentration anomaly is seen in the Barents Sea, with a decrease of almost 3\% averaged over the whole period (this is mainly a winter signal, since there is no sea ice in that region during the summer).

Many studies have shown that a link may exist between anomaly in sea ice concentration and changes in atmospheric

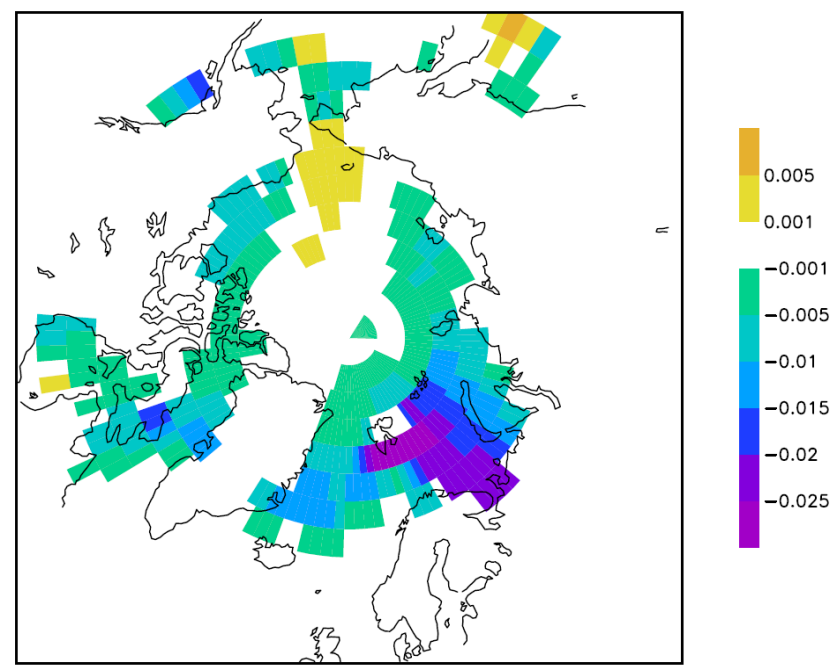

Fig. 8. Anomaly in annual mean sea ice concentration over the 1470-1520 warm period for the model results averaged over the 5 simulations with data assimilation. The reference period is 1600 1950 .

circulation (e.g. Slonosky et al., 1997; Alexander et al., 2004). In particular, because of the simulated reduction of sea ice cover in winter in the Barents Sea, the cold atmosphere is less isolated from the ocean, and is thus warmed by the oceanic heat fluxes. This warming can then impact on the atmospheric circulation. For instance, a reduction in Barents Sea ice coverage can trigger an important local decrease in atmospheric pressure, and thus, an enhanced cyclonic atmospheric circulation. (e.g., Guemas and Salas-Mélia, 2008). This anomaly in atmospheric circulation enhances the northward inflow of warm air into the Barents Sea region, favoring further melt of sea ice. Such a positive feedback mechanism has also been suggested previously by Goosse et al. (2003) in a study using an earlier version of LOVECLIM. Bengtsson et al. (2004) proposed as well that the anomaly in atmospheric circulation during the early 20th century warming in the Arctic was most likely induced by a reduced sea ice cover, mainly in the Barents Sea and that this circulation anomaly in turns strongly influences the ice concentration. Such a positive feedback could thus also play a role in both the persistence of the anomaly in atmospheric circulation and in sea ice concentration in the region of the Barents Sea during the period 1470-1520 obtained here.

Changes in oceanic circulation could also have an impact on regional temperature changes during the last millennium. However, the model does not simulate any clear oceanic signal during the period 1470-1520. For instance, Fig. 9 shows that the meridional transport of heat in the North Atlantic Ocean towards the Arctic does not experience any large variations over the last millennium in our simulations. Consequently, our results do not support attribution of the warming observed in the Arctic Seas during the period 1470-1520 to 


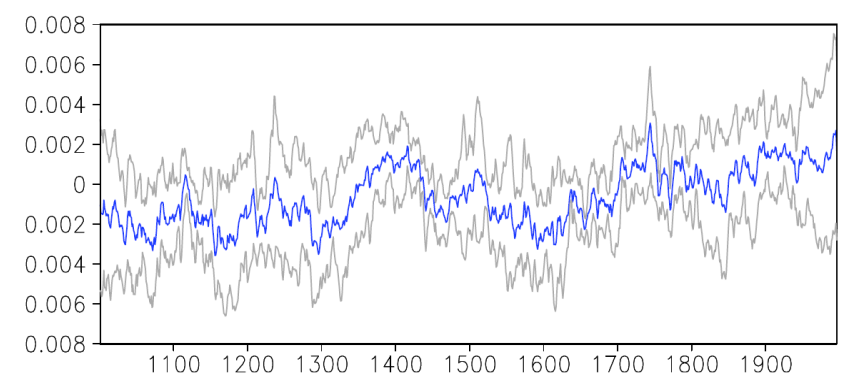

Fig. 9. Anomaly in meridional heat transport in the North Atlantic Ocean at $70^{\circ} \mathrm{N}(\mathrm{PW})$ for the average over the 5 model simulations performed with data assimilation, the grey lines are the mean plus and minus one standard deviation of the ensemble. A 51-year running mean has been applied to the time series. The reference period is $1600-1950$.

changes in oceanic circulation. A slight increase in the poleward heat transport is observed in our simulations over the course of the past millennium, bearing some similarity with the trend shown in Fig. 5a. Nevertheless, changes are not significantly different from zero. This weak oceanic response in the model may be due to the experimental design: we are not constraining directly the oceanic changes since the proxies selected for the data assimilation are located only on continents and continental shelves. Though some oceanic proxies at high latitudes are available, including, for instance, records derived from benthic and planktonic foraminifera, stable isotopes and diatom assemblages (Sicre et al., 2008; Eiriksson et al., 2006; Lund et al., 2006; Klitgaard Kristensen et al., 2004; Jiang et al., 2002; Mikalsen et al., 2001; Black et al., 1999), the number of continuous high-resolution marine sedimentary proxy records in the Arctic Ocean over the past millennium is rather small. Furthermore, the uncertainty associated with the calibration and dating of the marine records is generally larger than with other types of proxy records (Jones and Mann, 2004). As a consequence, incorporating such proxy data into our data assimilation procedure is not currently feasible. Most studies suggest that some regional temperature variability coincides with changes of oceanic circulation in the North Atlantic region, in particular, some indicate a role of the ocean in the Atlantic decadal variability. However, none of these studies highlight particular conditions during our period of interest that would suggest a clear underestimation of the role of the ocean in our simulations.

To conclude this section, we have compared qualitatively our model results with proxy data that have not been used in the data assimilation process. Some recent proxy-based reconstructions agree pretty well with our warm conditions during the 15 th and early 16 th century. For instance, a record of temperature based on sedimentary diatoms from a lake in Northern Fennoscandia (Weckström et al., 2006) shows a warm period during 1470-1500, which suits very well to our results. Bird et al. (2009) identified two relatively warm periods from 1350 to 1450 and 1500 to 1620 in a varvebased record from a lake in Alaska. The climate record inferred from varved lake sediments on Northeast Baffin Island studied by Thomas and Briner (2009) also suggests that the warmest pre-20th century interval during the last millennium occurred between 1375 and 1575. Finally, in an ice core record from Lomonosovfonna, Svalbard (Kekonen et al., 2005), the 15 th and mid-16th century corresponds to the warmest part of the $\delta^{18} \mathrm{O}$ profile. Sodium and chloride concentrations are high during this period, which is explained in the study of Kekonen et al. (2005) by a smaller sea ice extent, which allowed an increased sea-salt aerosols transport form the ocean. This reduced sea ice area is in accordance with the results obtained in our study. Furthermore, the higher sodium and chloride concentrations might possibly also suggest an increase in southerly winds intensity during that period, as proposed in our study.

\section{Conclusions}

In our simulations using LOVECLIM with data assimilation, we find the warmest pre-industrial conditions in the Arctic to have occurred during the period 1470-1520. During this period, the simulated temperatures are even higher than during the so-called "Medieval Warm Period". As the forced response of the model does not produce such an event, this warm period is interpreted as having resulted from internal adjustments of the climate system.

The advantage of the data assimilation technique used in this study is that we obtain a reconstruction of the climate of the past that is consistent with the proxy records, the forcing applied and the physical and dynamical processes included in the model. We can then provide additional information on a plausible large-scale pattern associated with the warming recorded locally in the proxies and on the dynamical processes that were responsible for this warming. There are still some limitations with this new method, and further refinements will be attempted in future studies. When combining proxies and model results, we benefit from the advantages of both proxies and models, but this also leads to some limitations. The assimilation of proxy data insures that the reconstructed climate follows, if imperfectly, the actual realization of internal climate variability experienced in the past climate evolution, while the use of physically-based model insures that the estimated climate history is consistent with basic climate physics and dynamical processes. This latter property of our approach allows us, furthermore, to interpret the estimated past climate history in terms of climate dynamical hypotheses. We cannot, however, deduce a precise explanation for the pattern of anomalies evident at any particular time, or the precise reason for the long-term persistence of particular patterns.

While not constituting a conventional detection/attribution analysis, our approach can nonetheless establish whether 
observed changes are consistent with the modeled response to forcing. For those changes which appear unrelated to any forcing, the most reasonable remaining hypothesis is that they arise from the internal variability of the system, though we cannot, of course, completely rule out a bias in the forcing time series used or in the model response to the forcing. It is important to keep in mind that LOVECLIM is a model of intermediate complexity and, by definition, its representation of atmospheric dynamics is simpler than in climate general circulation models. Such a simplified model is required in the context of studies such as ours, due to the high computational demand of the data assimilation technique. While LOVECLIM has been successfully employed in a number of past studies focused on the climate variability of the past millennium (e.g. Goosse et al., 2005), some caution is nonetheless advised in interpreting the dynamical response of the atmosphere to past forcing. For instance, the data assimilation scheme can induce a particular phase of the NAO during some periods that would be interpreted based only on LOVECLIM results as mainly due to internal variability, while in the real world (and in more sophisticated models), this can be largely attributed to a response of the system to the forcing and a much weaker contribution of the internal variability. Nevertheless, the volcanic and solar forcing did not appear to be particularly important during the period analyzed here.

Another limitation of our study is the low amount of data available. Because of the absence of proxy records in the central Arctic, our simulated pattern of anomaly can thus not be validated by observations there. Our results are then presented as hypotheses of changes, which could then be tested when new reconstructions become available, and used to provide information about mechanisms which could possibly explain the observed changes. It should be reminded that our results are certainly more robust in areas where a lot of proxies are available, such as over Scandinavia and Siberia.

Our model results clearly show that the simulated 14701520 Arctic warming is almost entirely explainable in terms of changes in atmospheric circulation, with a clear influence of the negative geopotential anomalies west of Iceland and in the North Pacific. The decrease in sea ice concentration in the Barents Sea region associated with the warming probably contributes to the persistence of those anomalies, at least in the European sector.

The patterns of surface temperature and sea level pressure over the years $1470-1520$ is somewhat similar to the early 20th century Arctic warm event. The available data indicates that the winter times in the 1920s were characterized by increased warm air inflow into Europe, while the Baffin Bay experienced a cooling. (Overland et al., 2004; Bengtsson et al., 2004). The pattern of sea level pressure (SLP) anomalies during this period is comparable with the pattern of the 14701520 warming period obtained in our model reconstructions (the geopotential height being the closest variable to the SLP in the model). The early 20th century warm event might thus not have been unique in the recent past. Furthermore, the negative anomaly centered over Bering Strait is responsible of the warming over the Canadian Archipelago. The relatively large event during the period 1470-1520 appears thus as a consequence of coincident changes in the European and Pacific sectors that also play a role in variations of Arctic climate during the 20th and early 21 st centuries (e.g. Overland and Wang, 2005).

No robust change in the patterns of oceanic circulation could be found in our model results to explain the changes observed in the Arctic Seas during the 1470-1520 warm event. The absence of strong response of the ocean in our simulations covering the past millennium may be due to the data assimilation and in particular to the lack of well calibrated oceanic proxies for the past millennium. Evidence has indeed been provided in past studies (e.g. Delworth and Mann, 2000; Knight et al., 2005) for the existence of a mode of multidecadal variability in the North Atlantic, related to fluctuations in the intensity of the thermohaline circulation. Such persistent patterns of variability could explain some of the low-frequency temperature variability observed at high latitudes (Zhang et al., 2007). The intensification of the Atlantic water inflow to the Arctic, which appears to explain some of the recent warming of the Arctic Ocean (Zhang et al., 1998; Gerdes et al., 2003), could provide an analog for past episodes of Arctic warming. As a consequence, additional work will be required both in terms of the implementation of the data assimilation technique and the inclusion of additional marine proxies, to investigate the role of oceanic circulation in past changes in the Arctic.

Acknowledgements. H. Goosse is Research Associate with the Fonds National de la Recherche Scientifique (FNRS-Belgium). This work is supported by the FNRS and by the Belgian Federal Science Policy Office, Research Program on Science for a Sustainable Development. M.E.M. gratefully acknowledges support from the ATM program of the National Science Foundation (Grant ATM-0542356). We would like to thank the three anonymous referees for their constructive criticism.

Edited by: D.-D. Rousseau

\section{References}

Alexander, M. A., Bhatt, U. S., Walsh, J. E., Timlin, M. S., Miller, J. S. and Scott J. D.: The atmospheric response to realistic Arctic sea ice anomalies in an AGCM during winter, J. Climate, 17, 890-905, 2004.

Bengtsson, L., Semenov, V. A., and Johannessen, O. M.: The early twentieth-century warming in the Arctic - a possible mechanism, J. Climate, 17, 4045-4057, 2004.

Berger, A.: Long-term variations of daily insolation and Quaternary climatic changes, J. Atmos. Sci., 35, 2363-2367, 1978.

Bird, B. W., Abbott, M. B., Finney, B. P., and Kutchko, B.: A 2000 year varve-based climate record from the central Brooks Range, Alaska, J. Paleolimnol., 41, 25-41, 2009. 
Black, D. E., Peterson, L. C., Overpeck, J. T., Kaplan, A., Evans, M. N., and Kasgarian M.: Eight centuries of North Atlantic Ocean variability, Science, 286, 1709-1713, 1999.

Briffa, K. R., Osborn, T. J., Schweingruber, F. H., Harris, I. C., Jones, P. D., Shiyatov, S. G., and Vahanov E.A.: Low-frequency temperature variations from a northern tree ring density network, J. Geophys. Res., 106, 2929-2941, 2001.

Brohan, P., Kennedy, J. J., Haris, I., Tett, S. F. B., and Jones, P. D.: Uncertainty estimates in regional and global observed temperature changes: a new data set from 1850, J. Geophys. Res., 111, doi: 10.1029/2005JD006548, 2006.

Brovkin, V., Bendtsen, J., Claussen, M., Ganopolski, A., Kubatzki, C., Petoukhov, V., and Andreev, A.: Carbon cycle, vegetation and climate dynamics in the Holocene: experiments with the CLIMBER-2 model, Global. Biogeochem. Cy., 16, doi: 10.1029/2001GB001662, 2002.

Charlson, R. J., Langner, J., Rodhe, H., Leovy, C. B., and Warren, S. G.: Perturbation of the Northern Hemisphere radiative balance by scattering from anthropogenic sulfate aerosols, Tellus, 43AB, 152-163, 1991.

Crowley, T. J.: Causes of climate change over the past 1000 years, Science, 289, 270-277, 2000.

D'Arrigo, R. and Jacoby, G. C.: Secular trends in high northern latitude temperature reconstructions based on tree rings, Clim. Change, 25, 163-177, 1993.

Delworth, T. L. and Knutson, T. R.: Simulation of early 20th century global warming, Science, 287, 2246-2250, 2000.

Delworth, T. L. and Mann, M. E.: Observed and simulated multidecadal variability in the Northern Hemisphere, Clim. Dynam., 16, 661-676, 2000.

Driesschaert, E., Fichefet, T., Goosse, H., Huybrechts, P., Janssens, I., Mouchet, A., Munhoven, G., Brovkin, V., and Weber N.: Modeling the influence of Greenland ice sheet melting on the Atlantic meridional overturning circulation during the next millennia, Geophys. Res. Lett., 34, L10707, doi:10.1029/2007GL029516, 2007.

Eiriksson, J., Bartels-Jónsdóttir, H. B., Cage, A. G., Gudmundsdóttir, E. R., Klitgaard-Kristensen, D., Marret, F., Rodrigues, T., Abrantes, F., Austin, W. E., Jiang, H., Knudsen, K. L., and Sejrup, H. P.: Variability of the North Atlantic current during the last 2000 years based on shelf bottom water and sea surface temperatures along an open ocean/shallow marine transect in western Europe, The Holocene, 16, 1017-1029, 2006.

Esper, J., Cook, E. R. and Schweingruber, F. H.: Low-frequency signals in long tree-ring chronologies for reconstructing past temperature variability, Science, 295, 2250-2253, 2002.

Gerdes, R., Karcher, M. J., Kauker, K., and Schauer, U.: Causes and development of repeated Arcitc Ocean warming events, Geophys. Res. Lett., 30(19), 1980, doi:10.1029/2003CL018080, 2003.

Goosse, H. and Fichefet, T.: Importance of ice-ocean interactions for the global ocean circulation: a model study, J. Geophys. Res., 104, 23337-23355, 1999.

Goosse, H., Selten, F. M., Haarsma, R. J., and Opsteegh, J. D.: Large sea-ice volume anomalies simulated in a coupled climate model, Clim. Dynam., doi:10.1007/s00382-002-0290-4, 2003.

Goosse, H. and Renssen H.: Exciting natural modes of variability by solar and volcanic forcing: idealized and realistic experiments, Clim. Dynam., 23, 153-163, doi:10.1007/s00382-004- 0424-y, 2004.

Goosse, H., Renssen, H., Timmermann, A., and Bradley R. S.: Internal and forced climate variability during the last millennium: a model-data comparison using ensemble simulations, Quater. Sci. Rev., 24, 1345-1360, 2005.

Goosse, H., Renssen, H., Timmermann, A., Bradley, R. S., and Mann, M. E.: Using paleoclimate proxy-data to select optimal realisations in an ensemble of simulations of the climate of the past millennium, Clim. Dynam., 27, 165-184, 2006.

Goosse, H., Driesschaert, E., Fichefet, T., and Loutre, M. F.: Information on the early Holocene climate constrains the summer sea ice projections for the 21 st century, Clim. Past, 3, 683-692, 2007, http://www.clim-past.net/3/683/2007/.

Goosse, H., Mann, M. E., and Renssen, H.: What we can learn from combining paleoclimate proxy data and climate model simulations of past centuries, in: Natural Climate Variability and Global Warming: a Holocene Perspective, Blackwell Publishing, 163-188, 2008.

Goosse, H., Lefebvre, W., de Montety, A., Crespin, E., and Orsi, A.: Consistent past half-century trends in the atmosphere, the sea ice and the ocean at high southern latitudes, Clim. Dynam., doi:10.1007/s00382-008-0500-9, 2009.

Guemas, V. and Salas-Mélia, D.: Simulation of the Atlantic meridional overturning circulation in an atmosphere-ocean global coupled model. Part II: weakening in a climate change experiment: a feedback mechanism, Clim. Dynam., 30, 310-844, doi:10.1007/s00382-007-0328-9, 2008.

Jacoby, G. C. and D'Arrigo, R.: Reconstructed Northern Hemisphere annual temperature since 1671 based on high-latitude tree-ring data from North America, Clim. Change, 14, 39-59, 1989.

Jansen, E., Overpeck, J., Briffa, K. R., Duplessy, J.-C., Joos, F., Masson-Delmotte, V., Olago, D., Otto-Bliesner, B., Peltier, W. R., Rahmstorf, S., Ramesh, R., Raynaud, D., Rind, D., Solomina, O., Villalba, R. and Zhang, D.: Palaeoclimate, in: Climate Change 2007: The Physical Science Basis. Contribution of Working Group I to the Fourth Assessment Report of the Intergovernmental Panel on Climate Change, edited by: Solomon, S., Qin, D., Manning, M., Chen, Z., Marquis, M., Averyt, K. B., Tignor, M. and Miller, H. L., Cambridge University Press, 433497, 2007.

Jennings, A. E. and Weiner, N. J.: Environmental change in the eastern Greenland during the last 1300 years: evidence from foraminifera and lithofacies in Nansen Fjord, $68^{\circ} \mathrm{N}$, The Holocene, 6, 179-191, 1996.

Jiang, H., Seidenkrantz, M. S., Knudsen, K. L., and Eríksson, J.: Late-holocene summer sea-surface temperatures based on a diatom record from the north Icelandic shelf, The Holocene, 12, 137-147, 2002.

Jiang, H., Eiríksson, J., Schulz, M., Kudsen, K. L. and Seidenkrantz, M. S.: Evidence for solar forcing of sea surface temperature on the North Icelandic shelf during the late Holocene, Geology, 33, 73-76, 2005.

Johannessen, O. M., Bengtsson, L., Miles, M. W., Kuzmina, S. I., Semenov, V. A., Alekseev, G. V., Nagurnyi, A. P., Zakharov, V. F., Bobylev, L. P., Pettersson, L. H., Hasselmann, K., and Cattle, H. P.: Arctic climate change: observed and modelled temperature and sea-ice variability, Tellus, 56A, 328-341, 2004. 
Jones, P. D., Osborn, T. J., and Briffa, K. R.: The evolution of climate over the last millennium, Science, 292, 662-667, 2001.

Jones, P. D. and Mann, M. E.: Climate over past millennia, Rev. Geophys., 42, RG2002, doi:10.1029/2003RG000143, 2004.

Kekonen, T., Moore, J., Perämäky, P., Mulvaney, R., Isaksson, E., Pohjola, V., and van de Wal, R. S. W.: The 800 year long ion record from the Lomonosovfonna (Svalbard) ice core, J. Geophys. Res., 110, D07304, doi:10.1029/2004JD005223, 2005.

Klitgaard Kristensen, D., Sejrup, H. P., Haflidason, H., Berstad, I. M., and Mikalsen, G.: Eight-hundred-year temperature variability from the Norwegian continental margin and the North Atlantic thermohaline circulation, Paleoceanography, 19, PA2007, doi:10.1029/2003PA000960, 2004.

Knight, J. R., Allan, R. J., Folland, C. K., Vellinga, M., and Mann, M. E.: A signature of persistent natural thermohaline circulation cycles in observed climate, Geophys. Res. Lett., 32, L20708, doi:10,1029/2005GL024233, 2005.

Kuzmina, S. I., Johannessen, O. M., Bengtsson, L., Aniskina, O. G., and Bobylev, L. P.: High northern latitude surface air temperature: comparison of existing data and creation of a new gridded data set 1900-2000, Tellus, 60A, 289-304, 2008.

Lund, D. C., Lynch-Stieglitz, J. L., and Curry, W. B.: Gulf Stream density structure and transport during the past millennium, Nature, 444, 601-604, 2006.

Mann, M. E. and Park, J., Global scale modes of surface temperature variability on interannual to century time scales, J. Geophys. Res., 99, 25819-25833, 1994.

Mann, M. E., Bradley, R. S., and Hughes, M. K.: Northern hemispheric temperatures during the past millennium: inferences, uncertainties, and limitations, Geophys. Res. Lett., 26, 759-762, 1999.

Mann, M. E. and Jones, P. D.: Global surface temperatures over the past two millennia, Geophys. Res. Lett., 30, 1820, doi:10.1029/2003GL017814, 2003.

Mann, M. E., Cane, M. A., Zebiak, S. E., and Clement, A.: Volcanic and solar forcing of the tropical pacific over the past 1000 years, J. Climate, 18, 447-456, 2005a.

Mann, M. E., Rutherford, S., Wahl, E., and Ammann, C.: Testing the fidelity of methods used in proxy-based reconstructions of past climate, J. Climate, 18, 4097-4107, 2005 b.

Mann, M. E., Zhang, Z., Hughes, M. K., Bradley, R. S., Miller, S. K., Rutherford, S., and Ni, F.: Proxy-based reconstructions of hemispheric and global surface temperature variations over the past two millennia, Proc. Natl. Acad. Sci., 105, 13252-13257, 2008.

Massé, G., Rowland, S. J., Sicre, M. A., Jacob, J., Jansen, E., and Belt, S.: Abrupt climate changes for Iceland during the last millennium: evidence from high resolution sea ice reconstructions, Earth Planet. Sci. Lett., 269, 564-568, 2008.

Meier, W., Stroeve, J., Fetterer, F., and Knowles, K.: Reductions in arctic sea ice cover no longer limited to summer, Eos Trans. AGU, 86(36), doi:10.1029/2005EO360003, 2005.

Mikalsen, G., Sejrup, H. P., and Aarseth, I.: Late-holocene changes in ocean circulation and climate: foraminiferal and isotopic evidence from Sulafjord, western Norway, The Holocene, 11, 437446, 2001

Moberg, A., Alexandersson, H., Bergstrom, H. and Jones P. D.: Were Southern Swedish summer temperatures before 1860 as warm as measured?, Int. J. Climatol., 23, 1495-1521, 2003.
Muscheler, R., Joos, F., Beer, J., Muller, S. A., Vonmoos, M., and Snowball, I.: Solar activity during the last $1000 \mathrm{yr}$ inferred from radionuclide records, Quaternary Sci. Rev., 26, 82-97, 2007.

Ogilvie, A. E. J. and Jónsson, T.: "Little Ice Age" Research: a perspective from Iceland, Clim. Change, 48, 9-52, 2001.

Opsteegh, J. D., Haarsma, R. J., Selten, F. M., and Kattenberg, A.: ECBILT: A dynamic alternative to mixed boundary conditions in ocean models, Tellus, 50A, 348-367, 1998.

Overland, J. E., Spillane, M. C., Percival, D. B., Wang, M., and Mofjeld, H. O.: Seasonal and regional variation of the Pan-Arctic surface air temperature over the instrumental record, J. Clim., 17, 3263-3282, 2004.

Overland, J. E. and Wang, M.: The third Arctic climate pattern: 1930s and early 2000s, Geophys. Res. Lett., 32, L23808, doi:10.1029/2005GL024254, 2005.

Overpeck, J., Hughen, K., Hardy, D., Bradley, R., Case, R., Douglas, M., Finney, B., Gajewski, K., Jacoby, G., Jennings, A., Lamoureux, S., Lasca, A., MacDonald, G., Moore, J., Retelle, M., Smith, S., Wolfe, A. and Zielinski, G.: Arctic environmental changes of the last four centuries, Science, 278, 1251-1256, 1997.

Polyakov, I. V. and Johnson, M. A.: Arctic decadal and interdecadal variability, Geophys. Res. Lett., 27, 4097-4100, 2000.

Przybylak, R.: Temporal and spatial variation of the surface air temperature over the period of instrumental observations in the Arctic, Int. J. Climatol., 20, 587-614, 2000.

Ramankutty, N. and Foley, J. A.: Estimating historical changes in global land cover: croplands from 1700-1992, Global Biogeochem. Cy., 13(4), 997-127, 1999.

Rogers, J. C.: Atmospheric circulation changes associates with the warming over the northern North Atlantic in the 1920s, J. Climate Appl. Meteor., 24, 1303-1310, 1985.

Serreze, M. C., Walsh, J. E., Chapin, F. S., Osterkamp, T., Dyurgerov, M., Romanovsky, V., Oechel, W. C., Morison, J., Zhang, T., and Barry, R. G.: Observational evidence of recent change in the northern high-latitude environment, Clim. Change, 46, 159-207, 2000.

Shindell, D. T., Schmidt, G. A., Mann, M. E., Rind, D., and Waple, A.: Solar forcing of regional climate change during the Maunder Minimum, Science, 294, 2149-2152, 2001.

Sicre, M.-A., Jacob, J., Ezat, U., Rousse, S., Kissel, C., Yiou, P., Eiríksson, J., Knudsen, K. L., Jansen E., and Turon, J.-L.: Decadal variability of sea surface temperatures off North Iceland over the last 2000 years, Earth Planet. Sci. Lett., 268, 137-142, 2008.

Slonosky, V. C., Mystak, L. A., and Derome, J.: Linking Arctic sea-ice and atmospheric circulation anomalies on interannual and decadal timescales, Atmos. Ocean, 35, 333-366, 1997.

Thomas, E. K. and Briner, J. P.: Climate of the past millennium inferred from a varved proglacial lake sediments on northeast Baffin Island, Arctic Canada, J. Paleolimnol., 41, 209-225, 2009.

Trenberth, K. E., Jones, P. D., Ambenje, P., Bojariu, R., Easterling, D., Klein Tank, A., Parker, D., Rahimzadeh, F., Renwick, J. A., Rusticucci, M., Soden, B., and Zhai, P.: Observations: Surface and Atmospheric Climate Change, in: Climate Change 2007: The Physical Science Basis. Contribution of Working Group I to the Fourth Assessment Report of the Intergovernmental Panel on Climate Change, edited by: Solomon, S., Qin, D., Manning, M., Chen, Z., Marquis, M., Averyt, K. B., Tignor, M., and Miller, 
H. L., Cambridge University Press, 235-336, 2007.

Vinther, B. M., Andersen K. K., Jones, P. D., Briffa, K. R., and Cappelen, J.: Extending Greenland temperature records into the late eighteenth century, J. Geophys. Res., 111, D11105, doi:10.1029/2005JD006810, 2006.

Weckström, J., Korhola, A., Erästö, P., and Holmström, L.: Temperature patterns over the past eight centuries in the Northern Fennoscandia inferred from sedimentary diatoms, Quaternary Res., 66, 78-86, 2006.
Zhang, J., Rothrock, A., and Steele, M.: Warming of the Arctic Ocean by a strengthened Atlantic inflow: Model results, Geophys. Res. Lett., 25, 1745-1748, 1998.

Zhang, R., Delworth, T. L., and Held, I. M.: Can the Atlantic Ocean drive the observed multidecadal variability in Northern Hemisphere mean temperature?, Geophys. Res. Lett., 34, L02709, doi:10.1029/2006GL028683, 2007. 